\title{
Developmentally regulated changes in the glycoproteins of the equine embryonic capsule
}

\author{
J. G. Oriol ${ }^{1}$, F. J. Sharom ${ }^{2}$ and K. J. Betteridge ${ }^{1}$ \\ ${ }^{1}$ Departments of Biomedical Sciences and ${ }^{2}$ Chemistry and Biochemistry, University of Guelph, Guelph, \\ Ontario, N1G 2W1, Canada
}

\begin{abstract}
The embryonic capsule, which covers the equine blastocyst after it loses its zona pellucida, is composed of mucin-like glycoproteins. In the present study, we investigated both macroscopic and molecular changes in the capsule during development. The weight of the capsule increased from day 11-12 of pregnancy and reached a maximum at about day 18 , coinciding with the time during which the conceptus migrates extensively throughout the uterus. The sialic acid content of the capsule declined markedly from about day 16, the time of conceptus 'fixation' in the uterus, which suggests a unique developmentally regulated mechanism for the control of embryo mobility. These results lead us to propose that the capsule may have an anti-adhesion function in the developing conceptus, and that this effect could be regulated by the sugar side chains of the capsular glycoproteins. The glycosylation characteristics of the blastocyst coverings also underwent changes at about day 9 of pregnancy, which may be related to loss of the zona pellucida. An anti-capsule monoclonal antibody was raised and shown to recognize a tissue-specific antigen present only on the capsule and trophoblast. This antigen was present on the trophoblastic cells soon after the blastocyst is formed, reached a maximum concentration at about day 18 , and was absent after day 22 , coinciding with the disappearance of the capsule. Immunohistochemical studies indicate that the mucinlike capsular glycoproteins are secreted, at least in major part, by the trophoblast. The pattern of secretion of these glycoproteins and the coincidence of molecular changes with important events in early pregnancy strongly suggest that they play crucial roles in early embryonic development.
\end{abstract}

\section{Introduction}

Acellular blastocyst coverings, which replace the zona pellucida before implantation or attachment of the blastocyst to the endometrium, have been described in baboons, rabbits, fur seals, dogs, cats, badgers, mink, moles and horses (for references see Denker, 1977; Oriol et al., 1993) and probably also occur in bears (Wimsatt, 1963). Some histological studies of these coverings have led to the suggestion that they function as a barrier and delay the process of implantation, whereas other workers suggested that they mediate cell adhesion during the same process (see Denker, 1977). In addition, functions at the fetalmaternal interface are also likely to be important. For example, the oligosaccharides in coverings with a high glycoprotein content can be predicted to extend far above the trophectoderm, and may therefore be implicated in communication between the mother and conceptus during the preimplantation period. As such potential functions must change as development of the conceptus proceeds, it is important to understand the corresponding changes in the structure of the blastocyst coverings that may underlie their role in early pregnancy. It is in this general context that we have investigated the blastocyst covering of the horse, the equine capsule (Betteridge, 1989; Oriol et al., 1993).

Received 22 February 1993
In horses, the embryo enters the uterus as a late morula or early blastocyst, 5-6 days after ovulation (Oguri and Tsutsumi, 1972; Betteridge et al., 1982; Freeman et al., 1991). It maintains its spherical shape (Fig. 1) until about day 21 of gestation and does not establish a direct cellular attachment to the endometrium until about day 35 , the time of invasion of the chorionic girdle cells into the maternal endometrium (Allen et al., 1973). Transrectal echographic studies showed that the conceptus at first migrates extensively throughout the uterus, but its position becomes fixed at day 16 or 17 (Ginther, 1985). From about day 6 , an extracellular coat, the equine capsule (Fig. 1), is deposited on the inside of the zona pellucida (see Betteridge, 1989, for details). The zona pellucida is subsequently shed, but the capsule persists and completely envelops the conceptus, as it expands in diameter from 150$220 \mu \mathrm{m}$ at day 6 to $2.5-2.8 \mathrm{~cm}$ at about day 21 (Betteridge et al., 1982; Enders and Liu, 1991). We have demonstrated that this capsule contains glycoproteins resembling those of the mucin family (Oriol et al., 1993), which are known to provide a protective coating on epithelial cell surfaces, and to play a fundamental role in cell-cell interactions (Jentoft, 1990). Thus, the structure of the capsule is consistent with the possibility that it both plays a protective role, and participates in communications at the fetal-maternal interface (Flood et al., 1982). 

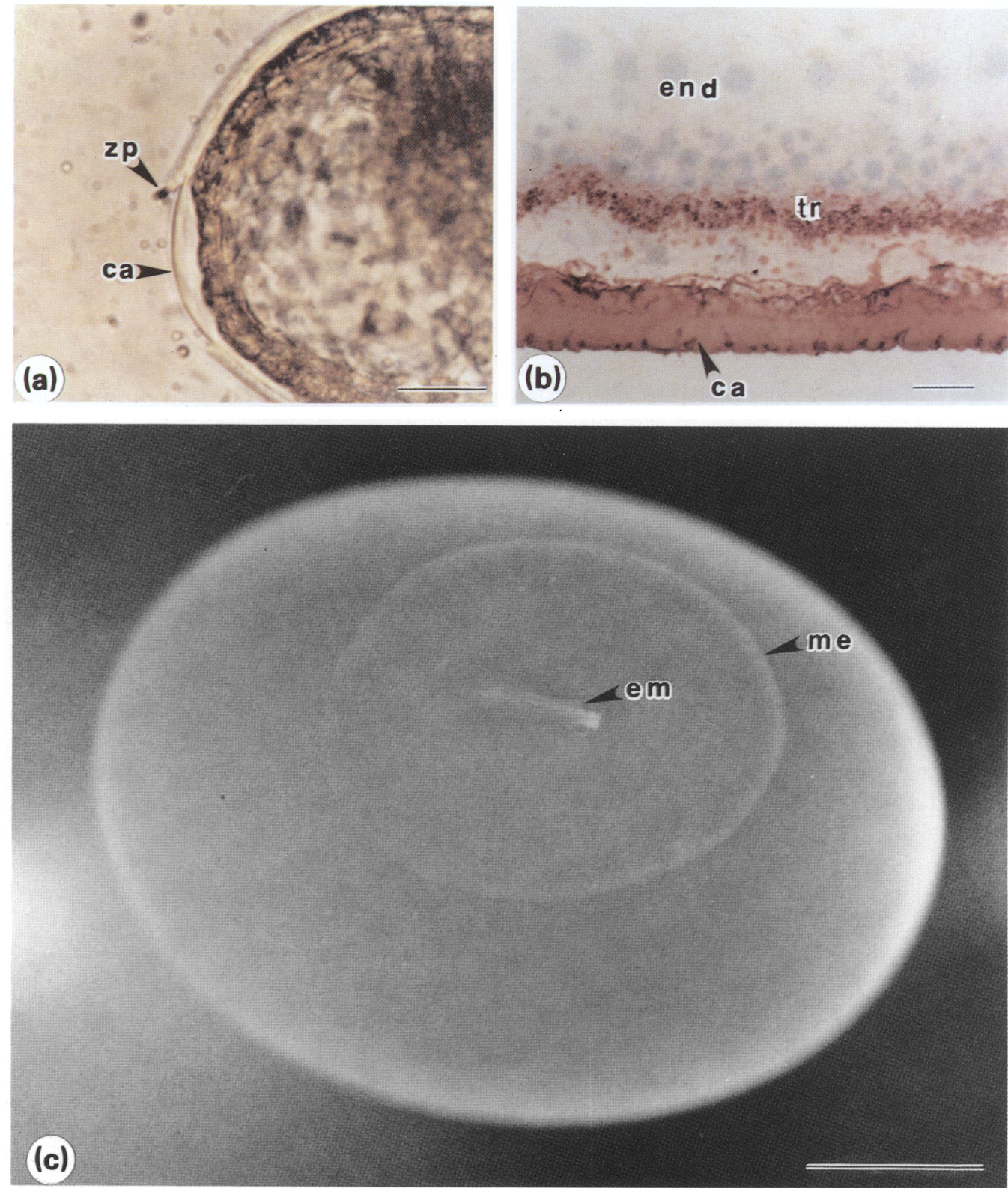

Fig. 1. The developing equine conceptus (ca: capsule; em: embryo; end: endoderm; me: mesoderm; tr: trophoblast; zp: zona pellucida) (a) Day 7.5 equine embryo showing the zona pellucida peeling off the underlying capsule. Scale bar represents $15 \mu \mathrm{m}$ (from Guillomot and Belteridge, 1984). (b) Photomicrograph of a frozen section of a day 12.5 conceptus stained (in red) with mouse anti-capsule polyclonal antibody, using an indirect immunoperoxidase assay. Scale bar represents $10 \mu \mathrm{m}$. (c) Day 18.5 equine conceptus showing its spherical shape, the embryo and the early stages of the mesoderm formation. In the embryo the cranial neural folds have formed, seven somites are present and the primitive streak has regressed to its caudal third. The boundary of the outgrowing mesoderm is prominent (arrow), but the acellular capsule, which is translucent, cannot be distinguished in the photograph. Transrectal echographic examination carried out before collection by uterine lavage showed the dimensions of the conceptus to be $2.9 \times 1.9 \mathrm{~cm}$. Scale bar represents $0.5 \mathrm{~cm}$.

As the horse trophoblast expresses many developmentally regulated, stage-specific molecules (for example MHC class I, Donaldson et al., 1990), the aims of this study were to determine the role of the trophoblast in capsular development, to investigate the molecular changes that occur in both the carbohydrate and polypeptide backbone of the capsule during development, and to link such changes to important gestational events. We have also studied the growth of the capsule during its development, for which currently available data are limited to observations on the thickness of the capsule up to day 16 of gestation (Flood et al., 1982). Accurately aged capsules were weighed and biochemically analysed for their amino acid and carbohydrate composition, and a monoclonal antibody $(\mathrm{mAb})$ raised against the capsular glycoproteins was used to study antigen expression on accurately aged trophoblast. 


\section{Materials and Methods}

\section{Animals}

A total of fifteen mares and two stallions belonging to the University of Guelph were used to obtain the equine conceptuses. Horses were housed at the Arkell Research Station, and the Equine Research Centre at the University of Guelph. The $\mathrm{BALB} / \mathrm{c}$ mice used for the production of $\mathrm{mAbs}$ were housed at the Central Animal Facility at the University of Guelph. All animal procedures were carried out using protocols approved by the Animal Care Committee.

\section{Tissue collection}

In total, forty-five accurately aged horse conceptuses were recovered by transcervical uterine lavage at various times between 6.5 and 34.5 days after ovulation, as previously described by Sirois and Betteridge (1988) and Oriol et al. (1989). During oestrus, mares were examined daily by transrectal echography for ovulation, which was defined as occurring midway between two consecutive examinations that revealed rupture of a follicle. Thus, the day on which rupture was detected was taken as day $0.5 \pm 0.5$. When the capsule was present (between days 6.5 and 22.5), it was removed (see below), washed in serum-free phosphate-buffered saline (PBS), $\mathrm{pH} 7.2$ and stored in PBS at $-20^{\circ} \mathrm{C}$.

The capsules of the four youngest conceptuses (earlier than day 9.5 , diameters $120 \mu \mathrm{m}$ to $2 \mathrm{~mm}$ ) were recovered using an inverted microscope, and these capsules may not have been collected intact. Twenty-four conceptuses obtained from days 9.5 to 16.5 of pregnancy (diameters $0.4-2.2 \mathrm{~cm}$ ) were obtained intact, and the remaining six collapsed during the collection process. However, in all cases, the capsules were easily dissected from the conceptus in a single piece, either under a stereomicroscope or using the naked eye. With the exception of one conceptus (Fig. 1), older conceptuses, between days 17.5 and 34.5 , were broken during the collection process. However, the capsules of the ten specimens collected before day 22.5 were recovered as ruptured structures in one piece.

Pieces of these conceptuses, and uterine biopsies taken from the donor mares after uterine lavage, were processed for immunohistochemical studies (see below). Additional samples of trophoblast (all ages), regressing yolk sac and allantochorion (day 11.5-34.5 conceptuses) and endometrium from pregnant and nonpregnant mares were obtained by dissection and snap-frozen at $-70^{\circ} \mathrm{C}$ in Optimum Embedding Compound (OCT: Miles Scientific, Toronto). Fourteen additional accurately aged capsules (between days 11.5 and 16.5) were kindly provided for these studies by K. Hinrichs (Tufts University, Boston) and D. C. Sharp (University of Florida, Gainesville) using similar collection procedures. Tissues from adult horses, collected post mortem at a local abattoir, were also snap-frozen in OCT for immunohistochemical studies, as were two sections of endometrial cup tissue from day 41 of pregnancy (kindly provided by W. R. Allen, Newmarket) and a single day 17.5 bovine conceptus.

\section{Amino acid analysis}

Amino acid analysis of capsular material was performed on a Beckman System Gold Amino Acid Analyser, using ninhydrin detection, as described by Oriol et al. (1993). Nine samples (two day 9.5, three day 13.5 , two day 15.5 and two day 21.5) were washed, and hydrolysed in $5.7 \mathrm{~mol} \mathrm{HCl} 1^{-1}$ at $108^{\circ} \mathrm{C}$ for $24 \mathrm{~h}$ in sealed evacuated tubes. Elution of amino acids after modification with ninhydrin was monitored by absorbance at $570 \mathrm{~nm}$, with the exception of proline, which was detected at $440 \mathrm{~nm}$.

\section{SDS-PAGE analysis}

Analysis was performed according to the method of Laemmli (1970), using a Mini-Protean II system (Bio-Rad Laboratories, Mississauga). Samples of capsular material from day 12.5, 15.5 and 21.5 conceptuses were solubilized with trypsin (Difco, Detroit, MI; $40 \mu \mathrm{g} \mathrm{ml}^{-1}$ for $12 \mathrm{~h}$ ) as described by Oriol et al. (1993) and separated on either a 12 or $15 \%$ polyacrylamide gel. Gels were then stained with silver according to Wray et al. (1981). In a typical experiment, a total of 3-5 $\mu \mathrm{g}$ capsular protein was loaded per well onto the electrophoretic gel.

\section{Dry weight analysis and protein determination}

Fifty-two capsules were washed extensively in distilled water, lyophilized and weighed three times on a microbalance. The average dry weight was recorded for each capsule. Protein was determined in some of the trypsin-solubilized capsules before analysis of sugar content, using the BCA protein assay system (Pierce Chemical Co., Rockford, IL), with BSA (Sigma Chemical Co., St Louis, MO; Type V, crystallized and lyophilized) as a standard.

\section{Analysis of sugars}

The content of the neutral sugars, mannose (Man), galactose (Gal), glucose (Glc) and fucose (Fuc), and the amino sugars, $\mathrm{N}$-acetylgalactosamine (GalNAc) and $\mathrm{N}$-acetylglucosamine (GlcNAc), in solubilized capsules was determined by highperformance anion-exchange chromatography (HPAEC) as described by Oriol et al. (1993). Sialic acid was determined using the 3-methyl-2-benzothiazoline hydrazone method described by Massamiri et al. (1979); $N$-acetyl-D-neuraminic acid (Sigma) served as the standard (see Oriol et al., 1993). For capsules with sufficient mass (usually older than day 16.5 of gestation), the same capsule was used for determination of amino sugar, neutral sugar and sialic acid. Two or three analyses for each sugar were carried out on the same capsule, depending on the material available.

\section{Immunization procedure and cell fusion}

Three ten-week-old female BALB/c mice (Charles River, St Constance, Québec) were immunized i.p. with a capsule glycoprotein suspension, after taking pre-immunization (control) retro-orbital blood samples. Day 13.5-15.5 capsules (kindly provided by B. A. Ball, Cornell University, Ithaca, NY) were sonicated for approximately $3 \mathrm{~min}$ in sterile distilled water. Each 
mouse was immunized three times at intervals of 3 weeks with approximately $400 \mu \mathrm{g}$ of tissue (from a pool of frozen capsules) in $0.4 \mathrm{ml}$ of sterile water for each immunization. Three weeks after the final immunization, blood samples were taken, and the serological responses evaluated using an immunohistochemical assay on cryostat sections of snap-frozen equine conceptus (see below). The mouse with the highest titre in the immunohistochemical assay was chosen for the fusion, and was given a booster injection of approximately the same amount of tissue as was used in the primary immunization. Three days later, cell fusion was performed according to standard techniques, using polyethylene glycol as the fusing agent (Goding, 1986). The yield of spleen cells from the mouse immunized with equine capsule was $7 \times 10^{7}$ cells, which was sufficient to seed five 96well plates at a 2:1 ratio of spleen cells to SP 2/0 myeloma cells (kindly provided by D. F. Antczak, Cornell University, Ithaca, NY).

\section{Immunohistochemical screening of sera and hybrid cell lines for antibody production}

Culture supernatants were tested for the presence of anticapsule antibody by indirect immunoperoxidase staining as described by Mason et al. (1982) and Antczak et al. (1987). Cryostat sections of whole day 11.5-12.5 horse conceptuses (four specimens) frozen at $-70^{\circ} \mathrm{C}$ in OCT embedding compound were used for screening the cell lines. Allantochorion, regressing yolk sac and adult tissues were used for antibody characterization. Tissues sections, $4-6 \mu \mathrm{m}$ thick, were cut using a cryostat at $-25^{\circ} \mathrm{C}$, and fixed for $10 \mathrm{~min}$ in acetone at $4^{\circ} \mathrm{C}$. The first stage reagents were either sera obtained from the mice before (negative control) or after immunization, or supernatants from microtitre plate wells containing hybrid cell lines. For immunohistochemical studies, anti-capsule $\mathrm{mAb}$ OC-1 (see below) was selected, and a $\mathrm{mAb}$ to canine parvovirus was used as the negative control (Parrish et al., 1982). The second stage reagent was horseradish peroxidase-conjugated goat anti-mouse Ig (heavy and light chains; Cappel Laboratories, Cochranville, PA), used at a dilution of 1:350 in Tris-buffered saline (TBS, $\mathrm{pH} 7.4$ ) containing $10 \%$ normal goat serum. The slides were developed with aminoethylcarbazole (AEC, Sigma) and counterstained with haematoxylin (Fisher Scientific, Unionville, Ontario). The intensity of immunohistochemical labelling by $\mathrm{mAb} O \mathrm{OC}-1$ in the tissues tested was assessed subjectively as negative, weak, strong or very strong. In addition, $\mathrm{mAb} O \mathrm{OC}-\mathrm{I}$ was tested for crossreactivity on samples of human and baboon placental tissues, and human somatic tissues, in the Third World Health Organization (WHO)-sponsored Workshop on Trophoblast Antigens (Rome, Italy, August 1992).

\section{Cloning and isotyping of cell lines}

The selected cell lines were cloned by limiting dilution as described by Pintus et al. (1983). Isotyping was performed using the Mouse-Typer Sub-Isotyping Kit (Bio-Rad). Briefly, the capsule was solubilized in trypsin $\left(40 \mu \mathrm{g} \mathrm{ml}^{-1}\right)$, adsorbed to a microtitre plate, then treated with $\mathrm{mAb}$ OC-1, OC-2 and OC-3. Bound $\mathrm{mAb}$ was reacted separately with each of the MouseTyper rabbit anti-mouse panel reagents (antisera to mouse
IgGI, IgG2a, IgG2b, IgG3, IgM, and IgA). Immunoglobulin class and subclass were then determined with goat anti-rabbit (heavy and light chains) horseradish peroxidase conjugate and a peroxidase substrate system. Colour development was immediate, and positive wells had absorbances eight times those of corresponding negative controls when read on an EIA reader (Titertek Multiskan Plus) at $490 \mathrm{~nm}$.

\section{Epitope determination}

Epitope determination was carried out using an assay described by Bara et al. (1992). Tissue sections from day 12.5 conceptuses were treated with periodate under mild conditions before immunohistochemistry, to determine whether destruction of the carbohydrate affected antibody reactivity. Briefly, each section was incubated for $30 \mathrm{~min}$ in $100 \mu \mathrm{l}$ of various concentrations of periodic acid (from $1 \mathrm{mmol} \mathrm{l}^{-1}$ to $20 \mathrm{mmol} \mathrm{l}^{-1}$, Fisher) diluted in acetate buffer, $0.05 \mathrm{~mol}^{-1}, \mathrm{pH} 5$. After three rinses with TBS containing $0.1 \%$ Tween 20 (Sigma), acidic reactive groups were neutralized with $1 \%$ glycine (Bio-Rad) for $30 \mathrm{~min}$. Sections were then rinsed three times in TBS-Tween 20 , and used immediately for conventional immunoperoxidase staining as described above. Control sections were incubated successively with the different buffered solutions, but periodic acid was omitted.

\section{Statistical analysis}

Dry mass and carbohydrate content of individual capsules were plotted against the age of the conceptuses. Regression analysis was performed on the linear scale and logarithmic values of the dry mass and sialic acid (Draper and Smith, 1981). In addition, the dry mass data were plotted as two time trends: a logarithmic scale up to day 18.5 and a linear scale from day 19.5 to day 22.5 (Draper and Smith, 1981).

\section{Results}

\section{Amino acid analysis}

Possible changes in the polypeptide backbone of mucin-like glycoproteins during development were investigated by subjecting washed capsules of various ages to amino acid analysis. The results (Table 1) show that no substantial differences in the amino acid content of the capsular glycoproteins could be detected during the development of the capsule.

\section{SDS-PAGE}

Trypsin-solubilized capsules were analysed by SDS-PAGE under reducing and non-reducing conditions, to investigate further possible changes at the protein level. The results (Fig. 2) show that no marked differences were apparent in the protein pattern of capsules of different ages; a prominent $21 \mathrm{kDa}$ band, representing approximately $40-70 \%$ of the total staining material, was the major feature. A similar band was obtained under non-reducing conditions (not shown), suggesting that 
Table 1. Amino acid composition of equine capsular glycoproteins

\begin{tabular}{|c|c|c|c|c|}
\hline \multirow[b]{2}{*}{ Amino acid } & \multicolumn{4}{|c|}{ Relative composition ${ }^{*}$} \\
\hline & Day $9.5^{* *}$ & Day $13.5^{* *}$ & Day $15.5 \dagger$ & Day $21.5^{* *}$ \\
\hline Glutamate/Glutamine & 2.42 & 2.44 & 2.32 & 2.36 \\
\hline Threonine & 2.07 & 2.07 & 1.89 & 1.86 \\
\hline Aspartate & 1.19 & 1.12 & 1.14 & 1.12 \\
\hline Valine & 1 & 1 & 1 & 1 \\
\hline Lysine & 0.99 & 0.85 & 1.05 & 1.05 \\
\hline Leucine & 0.80 & 0.80 & 0.80 & 0.86 \\
\hline Serine & 0.80 & 0.75 & 0.78 & 0.78 \\
\hline Isoleucine & 0.81 & 0.77 & 0.79 & 0.80 \\
\hline Proline & 0.69 & 0.67 & 0.63 & 0.62 \\
\hline Glycine & 0.59 & 0.58 & 0.58 & 0.59 \\
\hline Alanine & 0.60 & 0.57 & 0.55 & 0.58 \\
\hline Phenylalanine & 0.44 & 0.41 & 0.41 & 0.44 \\
\hline Arginine & 0.38 & 0.38 & 0.44 & 0.47 \\
\hline Methionine & 0.31 & 0.29 & 0.30 & 0.31 \\
\hline Histidine & 0.34 & 0.30 & 0.32 & 0.34 \\
\hline Tyrosine & 0.25 & 0.26 & 0.28 & 0.29 \\
\hline Hydroxylysine & ND & - & ND & ND \\
\hline Hydroxyproline & ND & - & ND & ND \\
\hline
\end{tabular}

${ }^{*}$ Valine was chosen as the standard for comparison. ${ }^{* *}$ Average of two capsules. † Average of five capsules. ND: not determined.

(a)

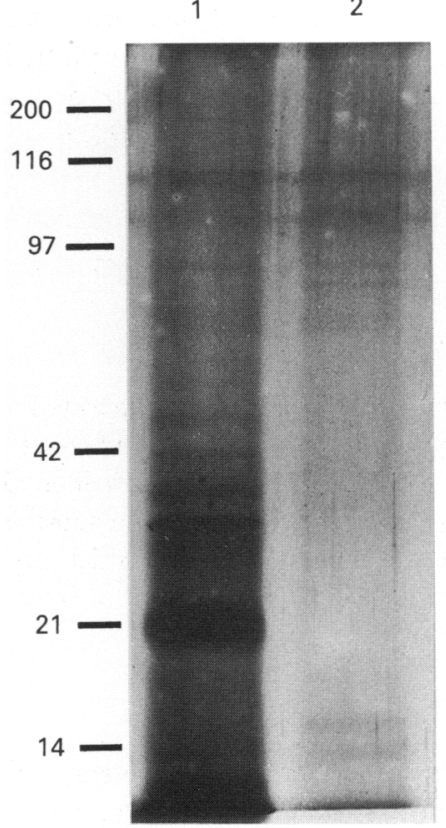

(b)
3
4
5

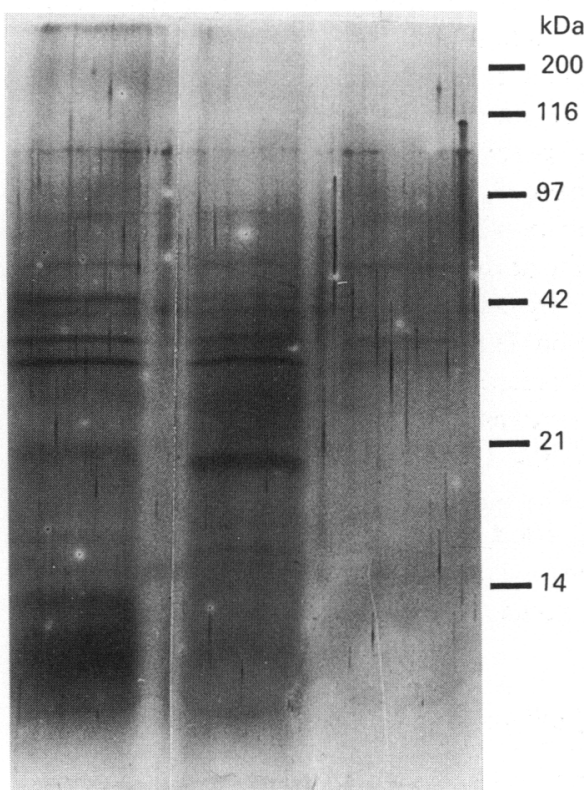

Fig. 2. Trypsin-solubilized equine capsule separated by SDS-PAGE on (a) $12 \%$ and (b) $15 \%$ acrylamide gels, and stained with silver. Solubilization of capsular material was carried out with $40 \mu \mathrm{g}$ trypsin $\mathrm{ml}^{-1}$ for $12 \mathrm{~h}$. Approximately 3-5 $\mu \mathrm{g}$ of solubilized capsular material was loaded per well into the electrophoretic gel. Lanes 1,3 and 4 show capsules obtained from day 15.5, 12.5 and 21.5 equine conceptuses, respectively. Note that a prominent $21-\mathrm{kDa}$ band is visible in all the preparations. Lanes 2 and 5 contained trypsin alone, as a control. 

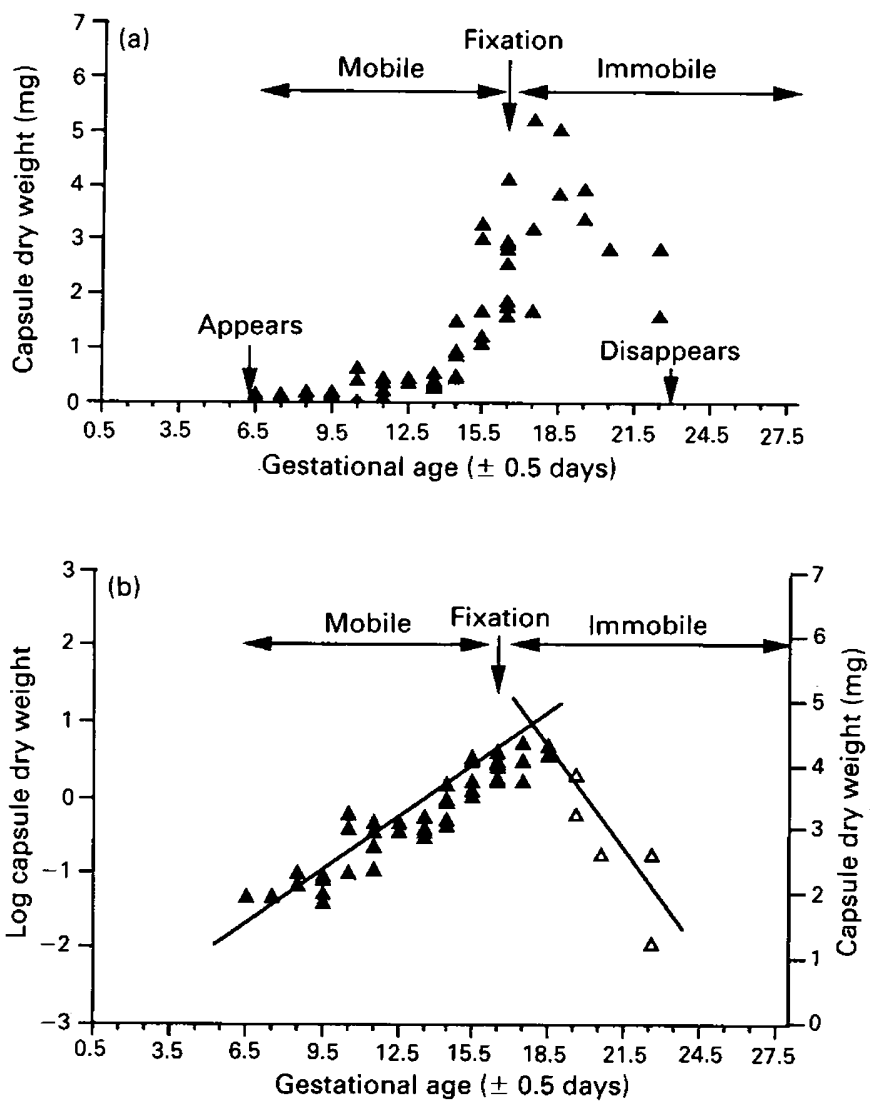

Fig. 3. Dry weights of capsules from fifty-two accurately aged equine conceptuses. The time of appearance and disappearance of the capsule, and the approximate time of 'embryo fixation', which separates the mobile and immobile phases of the time during which the conceptus is in the uterus, are indicated. (a) Data are shown on a linear scale; (b) the same data are plotted on a logarithmic scale up to day $18.5(\mathbf{A})$ and a linear scale from day 19.5 to day $22.5(\triangle)$. Several overlapping data points are presented on days 7.5, 9.5, 11.5, 13.5, 14.5 and 16.5 in (a). Note that the maximum dry weight is reached at about the time of embryo fixation.

disulfide bonds between Cys residues are not associated with this particular tryptic fragment.

\section{Determination of dry weight}

The overall development of the capsule was investigated by determining the growth in mass of this structure from its appearance at day 6.5 to its loss at day 22.5. The dry weight of the capsule did not increase significantly before day 11.5 of gestation (from $0.058 \pm 0.016 \mathrm{mg}$ at day $7.5, n=2$ to $0.228 \pm 0.147 \mathrm{mg}$ at day 11.5, $n=6$ ), but increased rapidly with blastocyst expansion between day 11.5 and day 18.5 (for example up to $4.45 \pm 0.83 \mathrm{mg}, n=2$ ) (Fig. 3a). The dry weight of the capsule then appeared to decrease until day 22.5 , shortly before its disappearance (to a mean of $2.22 \pm 0.86 \mathrm{mg}$ for the two specimens collected at day 22.5). Logarithmic transformation of the data showed a linear relationship, with a maximum point at day 18.5 (Fig. $3 \mathrm{~b}$ ). There was a negative regression after day 18.5 of gestation until shortly before the disappearance of the capsule at day 22.5. Regression analysis performed on the linear and logarithmic scale data showed $R$ values of 0.78 and 0.88 , respectively $(P>0.0001)$.

\section{Neutral and amino sugar content}

High-performance anion-exchange chromatography was used to determine the oligosaccharide composition of the capsular glycoproteins at various stages of development. GalNAC and Gal were present in relatively high equimolar amounts (ranging from 0.27 to $1.32 \mathrm{nmol} \mu \mathrm{g}^{-1}$ protein, and from 0.29 to $1.50 \mathrm{nmol}$ $\mu \mathrm{g}^{-1}$ protein, respectively) in capsules collected on or after day 10.5, whereas GlcNAc was found in much smaller amounts

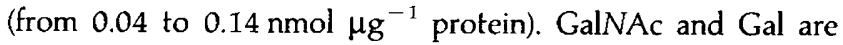
characteristically present in the $O$-linked oligosaccharides of the mucin family. There were no significant changes in GalNAc and Gal after day 10.5, and the Gal:GalNAc ratio (not shown) remained relatively constant. Mannose was absent on or after day 11.5. Capsules from earlier stages had low amounts of GalNAc and Gal, and relatively higher amounts of mannose (ranging from 0.060 to $0.078 \mathrm{nmol} \mu \mathrm{g}^{-1}$ during day $6.5-9.5$, compared with the range of $0.0-0.025 \mathrm{nmol} \mathrm{gg}^{-1}$ at days $12.5-$ 22.5). Mannose is characteristic of $N$-linked glycosylation, suggesting that small amounts of $\mathrm{N}$-linked oligosaccharides are present before day 9.5, when the zona pellucida might remain associated with the capsule. The GlcNAc:GalNAc ratios (Fig. $4 c$ ), which also reflect glycosylation differences during development, decreased markedly at the time of loss of the zona pellucida from the developing capsule (from 1.03 at day 7.5, $n=1$, to $0.18 \pm 0.05$ at day $10.5, n=3$ ). After day 10.5 the GlcNAc:GalNAc ratio did not change substantially $(0.150 \pm$ 0.04 for days 11.5 to $22.5, n=29$ ). These results strongly suggest that the amino sugar and neutral sugar content of the zona pellucida and the capsule are very different. In addition to the data presented (Fig. 4), the zona pellucida and capsule from one day 6.5 embryo (before the zona peels off) were analysed together. The GlcNAc:GalNAc ratio was determined to be 10.3, indicating that the amino sugars of the zona pellucida, unlike those of the capsule, consist predominantly of GlcNAc.

\section{Sialic acid content}

A colorimetric assay was used to determine the content of sialic acid in the capsule, which is known to play an important role in cell-cell interactions. On days $13.5-14.5$ the content of sialic acid was very high, ranging from $1.63 \pm 0.21$ to

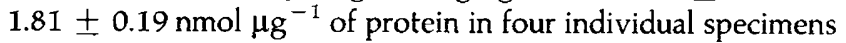
(Fig. 4d). However, after embryo 'fixation' at day 16.5, the amount of sialic acid in the capsular glycoproteins decreased to $0.86 \pm 0.15 \mathrm{nmol} \mu \mathrm{g}^{-1}$ protein in the three day 17.5 specimens. Linear regression analysis performed on the data showed an $R$ value of $0.88(P>0.0001)$. This result suggests that the capsular glycoproteins become desialylated at the time of embryo 'fixation'. It was not possible to determine the sialic acid content of capsules before day 13.5 , because of their very low mass.

\section{Monoclonal antibody production and initial characterization}

Four hundred and fifty wells (90\%) from the initial fusion showed hybridoma growth. Of those, supernatants from 220 

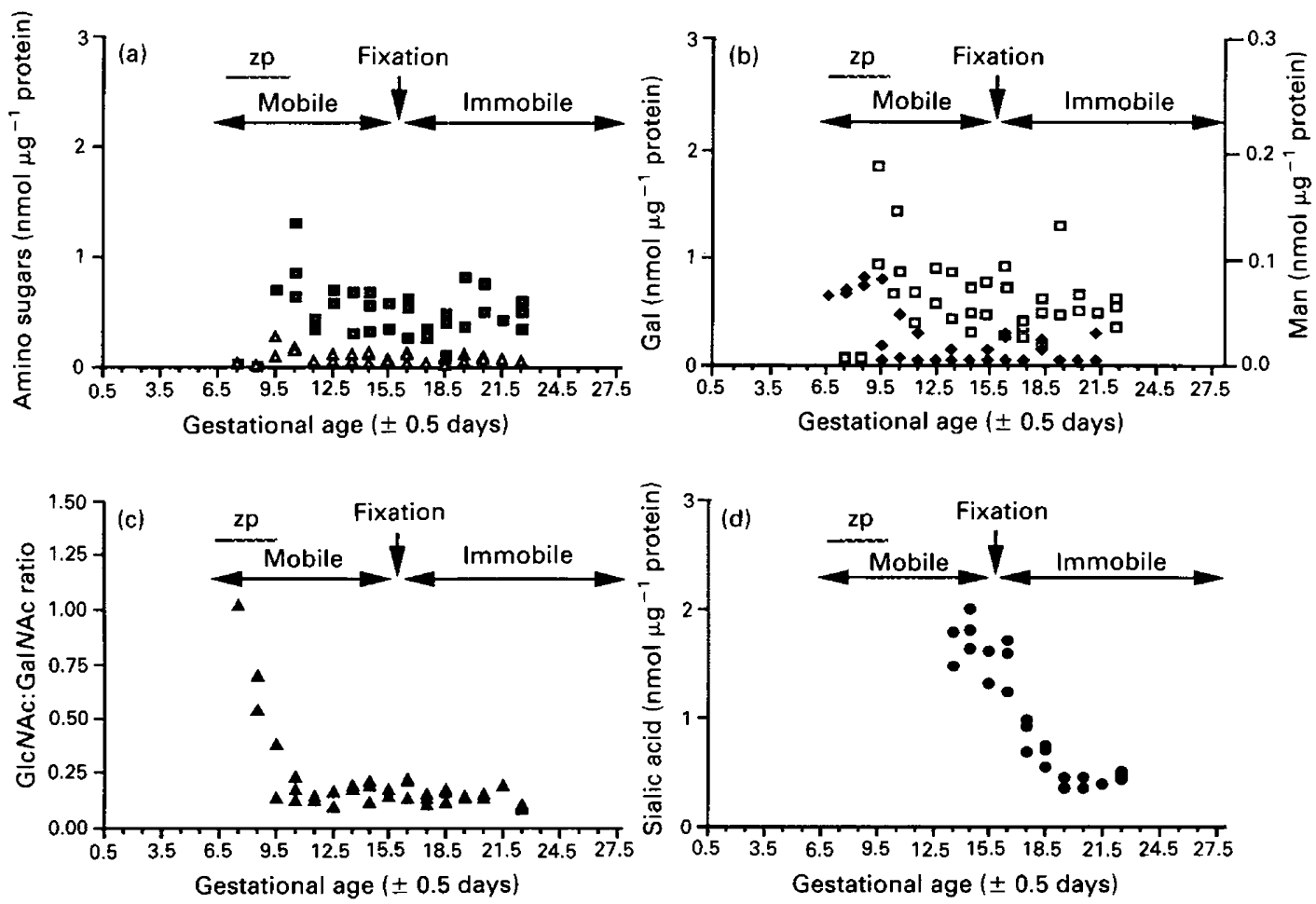

Fig. 4. Variations in amino sugar, neutral sugar and sialic acid content of the capsular glycoproteins with gestational age. Data are from thirty-seven conceptuses, with the exception of (d) ( $n=24$ ) (a) Amino sugars; GalNAc and GlcNAc; (b) neutral sugars; Gal and Man; (c) ratio of GlcNAc:GalNAc; (d) sialic acid. Sugar content is expressed as $\mathrm{nmol} \mu \mathrm{g}^{-1}$ protein, with the exception of (c). The time of embryo fixation, and the approximate time of the presence of the zona pellucida (zp), are indicated.

wells were tested for antibody production using an indirect immunoperoxidase assay. Three cell lines that reacted with capsule or trophoblast were selected, cloned and isotyped. The corresponding mAbs were named OC-1, OC-2 and OC-3. $\mathrm{MAb} O \mathrm{OC}-1$, an $\operatorname{lgG} 1$, reacted strongly with both the apical aspect of the trophoblast and the capsule. MAb OC-2, an IgG1, reacted weakly with the capsule alone, whereas $\mathrm{mAb} O C-3$, an IgG, reacted strongly with the trophoblast alone. MAbs OC-2 and $\mathrm{OC}-3$ were not used further in the present study, but the nature of their epitope was determined.

Reactivity of monoclonal antibody OC-1 with equine conceptuses at various ages

The changes occurring in OC-I antigen during embryonic development were determined by using $m A b$ OC- 1 in an immunohistochemical assay on frozen sections of equine placental tissues from day 11.5 to day 34.5 of pregnancy. The antibody labelling studies showed that the amount of OC-Ireactive antigen present in the trophoblast increased rapidly up to day 17.5 , decreased markedly by day 22.5 , and was completely absent after day 24.5 , following the disappearance of the capsule. These results indicate that $m A b$ OC- $I$ recognizes an antigen in the cytoplasm of the trophoblast which is only expressed during the period when the capsule is present. The apical surface of the trophoblastic cells was more strongly labelled (Fig. 5c, d), suggesting that OC-1-reactive antigen is probably present on an extracellular protein (or glycoprotein) secreted by the trophoblast. OC-I-reactive antigen was not detected in fetal endodermal tissue (from day 12.5 to day 34.5), nor in the chorionic girdle and endometrial cups, which form after disappearance of the capsule. In addition to these fetal membranes, three fetuses (ranging from day 26.5 to 34.5 of pregnancy) were tested using transverse sections of the whole embryo, and $\mathrm{mAb} O \mathrm{OC}-1$ again failed to label any tissue of the embryo. This result strongly suggests that the OC-1-reactive antigen is restricted to the capsule and the trophoblast tissue within the equine conceptus. Moreover, the changes in the density of OC-1-reactive antigen on the trophoblast (Fig. $5 \mathrm{~b}-\mathrm{d}$ ) correspond to the increase in the dry mass of the capsule (Fig. 3).

\section{Reactivity of monoclonal antibody OC-1 with adult equine tissues}

The presence of OC- 1 antigen in organs that interact with the developing embryo or capsule was determined by testing $\mathrm{mAb} O C-1$ on frozen sections of ovary (including oocytes), oviduct, and nonpregnant (oestrous and dioestrous) and pregnant endometrium. The mAb OC- 1 failed to label any of the reproductive organs tested (for example see Fig. $5 f$ ). In addition, eight other somatic tissues, several of epithelial origin (liver, trachea, lungs, tongue, stomach, small and large intestine, kidney) were tested for crossreactivity towards $M A b$ OC-1, and no reactivity was observed with any of them. These results indicate that OC-1-reactive antigen is not expressed at a detectable level in the adult tissues tested. 

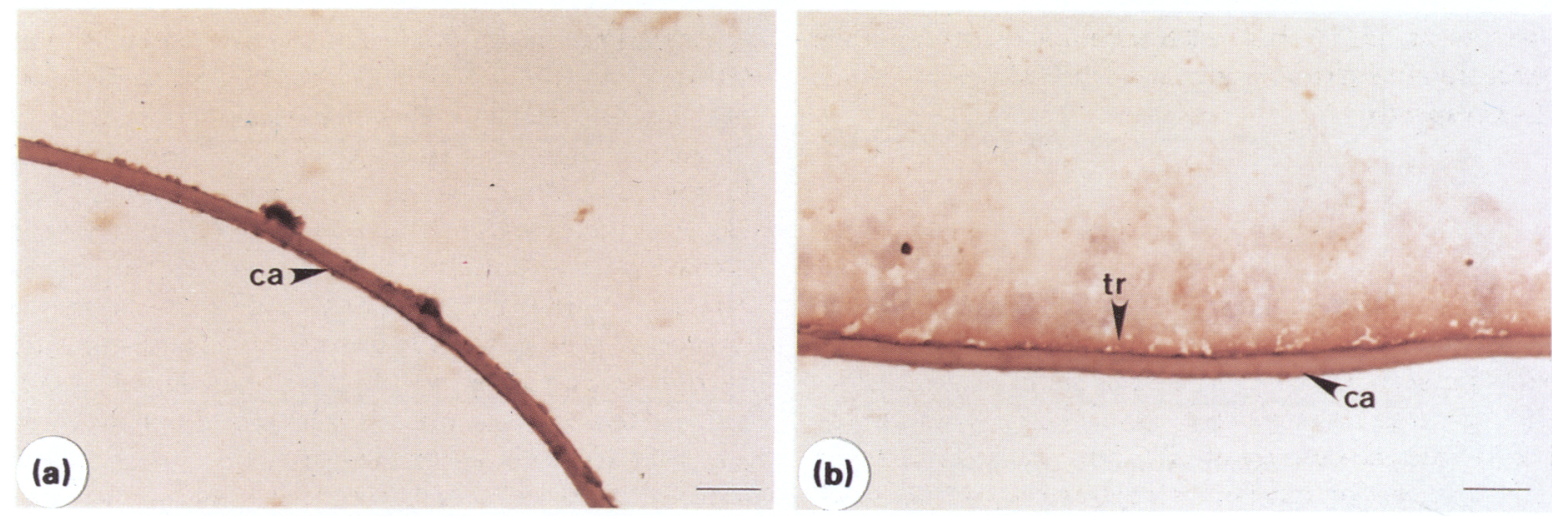

(b)
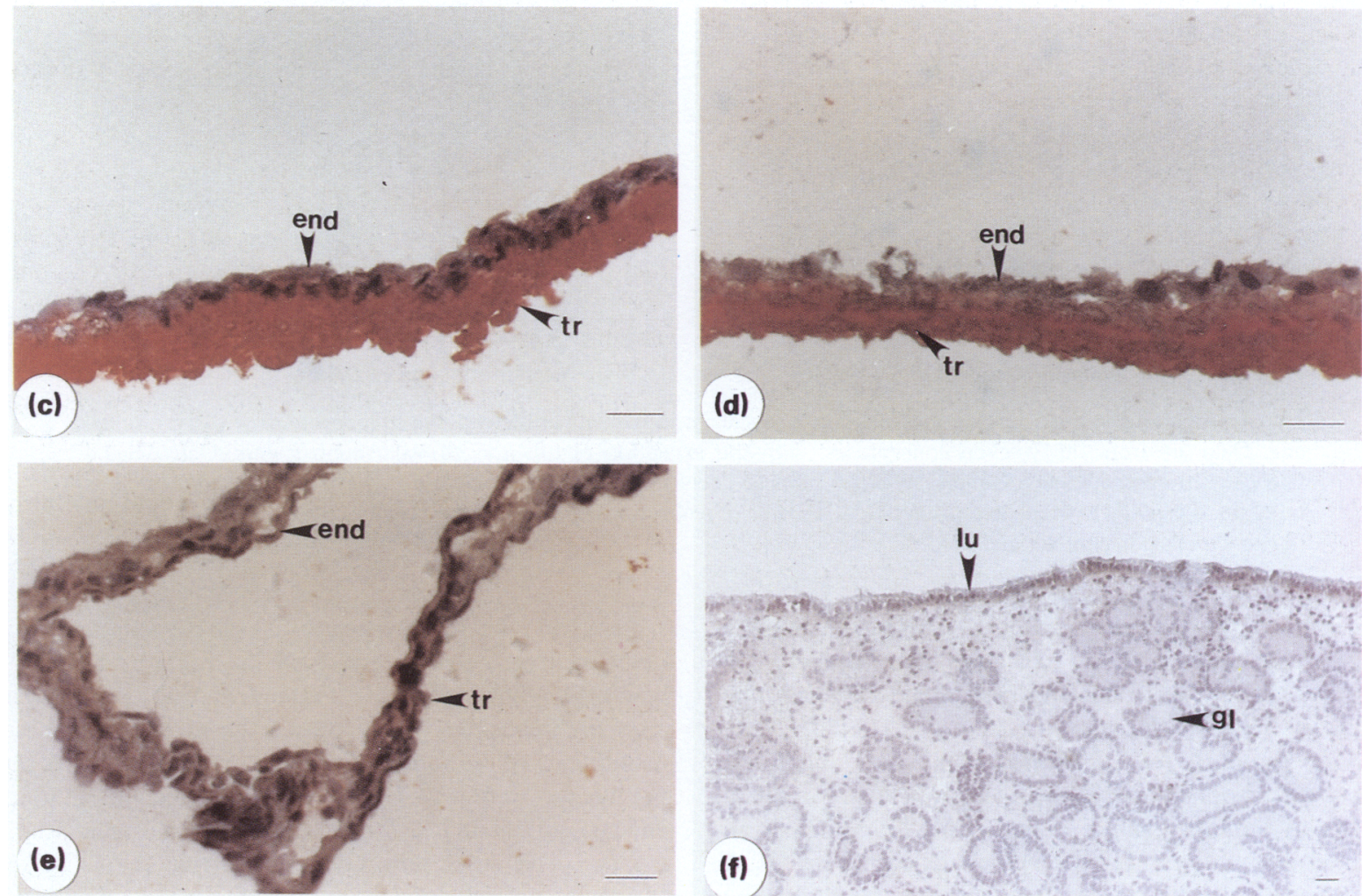

(d)

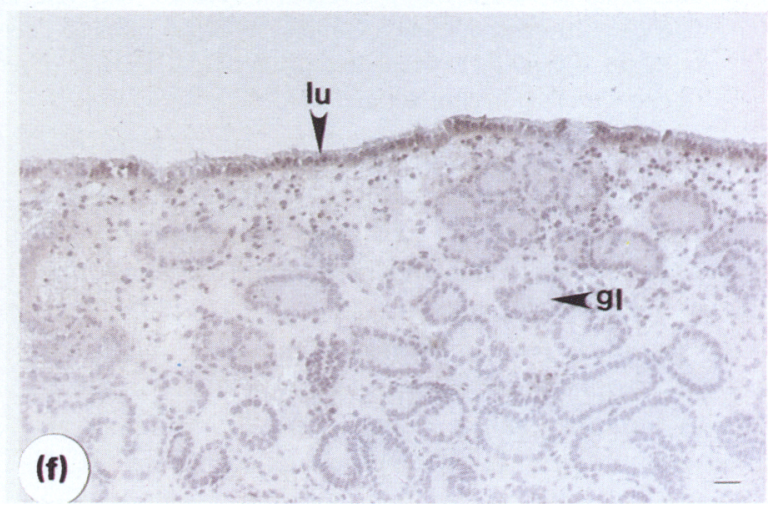

Fig. 5. Photomicrographs of frozen sections of horse tissues labelled with anti-capsule mAb OC-1 using an indirect immunoperoxidase assay (ca: capsule; tr: trophoblast; end: endoderm; lu: luminal epithelium; gl: glandular epithelium). Scale bar represents $10 \mu \mathrm{m}$. (a) Day 14.5 equine capsule. The capsule is strongly labelled. (b) Day 12.5 equine conceptus. The outer cell layer of the trophoblast is strongly labelled. The inner layer of the capsule is strongly labelled, and the outer layer also shows labelling. (c) Day 17.5 equine conceptus. The labelling of the trophoblast is very strong, but the endoderm cells are negative. The capsule is not in the photomicrograph. (d) Day 22.5 equine conceptus. The intensity of the labelling of the trophoblast is weaker than in the day 17.5 trophoblast shown in (c). (e) Day 24.5 conceptus. The trophoblast and the endoderm are negative. Compare the labelling intensity of (b) to (e) with the dry weight of the capsule (Fig. 3). (f) Day 16.5 nonpregnant endometrium. There is no labelling of the luminal and glandular epithelium, nor of the stroma. The same results were obtained with adult tissues, including pregnant endometrium, and with fetuses.

\section{Epitope determination}

Carbohydrate epitopes are almost completely destroyed by periodate, while peptide epitopes are well preserved with periodate under mild conditions. MAbs OC-1 and OC-3 showed similar immunoreactivity with the capsule and trophoblast before and after oxidation (up to $20 \mathrm{mmol}$ sodium periodate $1^{-1}$ ), but mAb OC-2 failed to react after treatment of the tissue sections with only $5 \mathrm{mmol}$ sodium periodate $\mathrm{I}^{-1}$.
Crossreactivity of $m A b O C-1$ with tissues from other mammals

The antibody failed to label the trophoblast, mesoderm or endoderm in cryostat sections of a day 17.5 bovine conceptus. Mesenchyme and endothelium from human term placenta and human skin, tongue, thyroid and oesophagus gave positive results on immunohistochemical assay, whereas no reaction was observed with either human (first trimester) or baboon placental tissues. Interestingly, OC-1 antibody crossreacted with normal 
human sera in an ELISA test. Interpretation of these results awaits more detailed characterization of the epitope for which $\mathrm{mAb} O C-1$ is specific.

\section{Discussion}

We have previously shown that the extracellular capsule of the equine conceptus is composed of mucin-like glycoproteins that are heavily $O$-glycosylated mainly on threonine residues (Oriol et al., 1993). A large fraction (5I-57\%) of the total amino acid content of the capsule consists of Gly, Thr, Ser, Pro and Ala, a profile characteristic of mucins, as reported by Oriol et al. (1993). The results presented here clearly indicate that the mucinlike capsular glycoproteins are developmentally regulated. Dry weight and immunohistochemical analysis showed that the maximum weight, and probably production, of the capsule is attained at about day 18. In addition, modification of the $O$-linked oligosaccharides of the capsular glycoproteins was correlated with important events during early pregnancy. In contrast, amino acid analysis showed no substantial difference in the amino acid composition of young and old capsules (from days 9.5 to 21.5), suggesting that the polypeptide backbone of the capsular glycoproteins does not change substantially during development. However, we cannot rule out the possibility that a new protein with similar structure, and similar overall amino acid composition, might be added to the original capsule during this period. In this context, the zona pellucida of several species is known to incorporate oviductal components during the passage of the fertilized oocyte through the oviduct (for example; in hamster, St-Jacques et al., 1992; Abe et al., 1992), and so it is possible that the capsule might similarly incorporate uterine proteins.

The equine capsule is highly resistant to solubilization by chemical and enzymatic means, and can be studied biochemically only after proteolysis (Oriol et al,, 1991a, 1993). Consequently, uncertainties arise concerning the complete structure of the glycopeptides. SDS-PAGE analysis has shown that the $21-\mathrm{kDa}$ band, which we have previously suggested to arise from unglycosylated regions (Oriol et al., 1993), was observed from day 12.5 to 21.5 of gestation. Variations in intensity of this and other bands may arise from differences in the trypsin solubilization process, which is currently under investigation. The accessibility of the $21-\mathrm{kDa}$ peptide of the capsule to proteases might not change significantly during this period. These data further support our conclusion that the polypeptide backbone of the capsular glycoproteins does not undergo substantial modifications during development.

The capsular glycoproteins are a good model of regulation (at both the biochemical and morphological level) during a welldefined period of embryogenesis. Other investigators have attempted to determine the growth of blastocyst coverings by measuring their thickness under the electron microcope (Flood et al., 1982; Leiser and Denker, 1988). However, that approach suffers from the fact that the degree of shrinkage of the coverings arising from dehydration and the embedding process is unknown. Thus, the dry weight data presented here are perhaps a more accurate way of reflecting the growth characteristics of the capsule in vivo.

The equine conceptus migrates extensively until day 17 when its position becomes fixed (Ginther, 1985). This mobility is necessary to inhibit production of endometrial prostaglandins (Sharp et al., 1989). The rapid production of capsular glycoproteins that we have shown to occur during this phase of pregnancy suggests that they have anti-adhesion properties. In support of this hypothesis, highly sialylated membraneassociated mucins have been shown to reduce cellular adhesion markedly (reviewed by Hilkens et al, 1992). For example, carcinoma cells with overexpression of mucin-like anti-adhesion molecules grow partially in suspension (Ligtenberg et al., 1992) or lose their invasive properties on collagen gels (Frixen $e t$ al, 1991). Thus, the increase in capsule dry mass up to day 18.5 may reflect a need to keep the growing conceptus covered to facilitate its mobility, and the decline in capsular production after day 18.5 might be associated with the loss of conceptus mobility.

Changes in dry mass of the capsule, and the correspondence of these with OC-1-reactive antigen expression, indicate that secretion of the capsular glycoproteins is developmentally regulated, and suggest that they may be major products of the preattachment equine conceptus. It is interesting that the pattern of their production seems to coincide with that found in the only report on horse trophoblast interferons (Zouari et al., 1991), which are secreted at much lower concentrations than in sheep, cattle and pigs (Roberts, 1989; La Bonnardière et al., 1991).

Using a high resolution lectin-gold approach and quantitative analysis, Roux and Kan (1991) showed changes of the glycoconjugates in the hamster zona pellucida during oocyte growth and development in the ovary and oviduct. Some of the compositional changes of the capsular carbohydrates that we have demonstrated during development may be related to the loss of the zona pellucida, fragments of which can remain associated with the capsule up until at least day 9.5 of pregnancy (Bousquet et al., 1987). Physical, immunological and chemical differences between the zona pellucida and the capsule have been demonstrated (Bousquet et al., 1987; Oriol et al., 1993), and the results of carbohydrate analysis also show that there are important glycosylation differences between these structures. The high mannose content and GlcNAc:GalNAc ratio observed before the loss of the zona pellucida presumably indicate that the zona pellucida, unlike the capsule (Oriol et al., 1993), contains high amounts of $N$-linked oligosaccharides. Substantial amounts of $\mathrm{N}$-linked glycoproteins are known to be present in murine and porcine zonae pellucidae (for references see Wassarman, 1988) and it is likely that this pattern is also exhibited by glycoproteins of equine zonae pellucidae (Miller et al., 1992, 1993).

Changes on the cell surface that modulate adhesion have been associated with the complex carbohydrate moieties of glycoproteins, glycolipids and glycosaminoglycans located within the glycocalyx (Wordinger and Amsler, 1980; Guillomot et al., 1982; Whyte and Allen, 1985; Chávez, 1986; Murphy and Turner, 1991). In addition, it has been suggested that embryo hatching in mice may be regulated by surface glycoproteins (Glass et al., 1979). The proposed anti-adhesion function of the capsule up to day 17 could be regulated by the sugar sidechains of the capsular glycoproteins, which carry many sialic acid residues (approximately $57-65 \%$ of the total carbohydrate; Oriol et al., 1993). The resulting high negative charge may prevent adhesion to the endometrium by a charge repulsion effect. 
Thus, the loss of sialic acid from the capsular glycoproteins would abolish the anti-adhesion effect, coincident with 'fixation' at the future site of placentation at the end of the mobile phase. An anti-adhesive effect of sialic acid has been demonstrated in other mucin-like molecules such as episialin (Hilkens et al., 1992), and in neural cell adhesion molecules (Yang et al., 1992). Both glycoproteins prevent cell adhesion, but this property is diminished by loss of sialic acid (Ligtenberg et al., 1992; Yang et al., 1992). Thus, 'fixation' of the equine embryo may also be regulated by surface sialic acid. Further studies are needed to determine whether the trophoblast or endometrial tissues or both are responsible for the desialylation process at the time of conceptus 'fixation' in horses. It will also be important to determine whether sialic acid is lost from the blastocyst coverings of other species during development.

To our knowledge, OC- 1 is the first $m A b$ reported to recognize specifically a blastocyst covering other than zona pellucida in any species. The use of $\mathrm{mAb} O \mathrm{OC}-1$ showed that the trophoblastic cells participated in the synthesis of OC-1-reactive antigen very soon after the blastocyst was formed. Moreover, the expression of OC-1-reactive antigen on the apical surface of the trophoblast appears to be stage and tissue specific, coinciding with the time of maximal accumulation of capsular glycoproteins. This finding suggests that the capsular glycoproteins are produced in the cellular compartment of the trophoblast cells, although the proteins may be assembled into a sheet-like structure extracellularly, as occurs in mucins (Lamblin et al., 1991). MAb OC-1 did not react with luminal or glandular epithelium of the pregnant and nonpregnant endometrium. During other immunological studies of surface antigen expression in equine trophoblast populations (Antczak et al., 1987; Oriol et al., 1989), no mAb reacting with an epitope on both the capsule and equine trophoblast was identified, and downregulation of surface epitopes occurred only after day 34 (Donaldson et al., 1990; Oriol et al., 1991b). This finding suggests that the mAbs involved in those studies were not directed against capsular components.

The relatively widespread existence of blastocyst coverings in eutherians suggests that $m A b$ OC- 1 recognizes an analogous epitope in other mammals. However, we have not been able to demonstrate OC-I-reactive antigen in several conceptuses with or without coverings (baboon, human, bovine). It will be important to extend these studies to other eutherian and metatherian conceptuses.

Periodate pretreatment of sections of gastrointestinal mucosae before immunohistochemical assay has previously been used to characterize the carbohydrate or peptide nature of twenty-two well known mucin epitopes (Bara et al., 1992). In the present study, periodate-treated sections of equine conceptuses were used to investigate the epitopes of the three $\mathrm{mAbs}$ raised. Only $\mathrm{mAb} O \mathrm{OC}-2$ failed to react with periodatetreated sections, suggesting that either it was the only $m A b$ raised against a carbohydrate epitope, or that it was the only $\mathrm{mAb}$ with an epitope susceptible to oxidation. MAbs OC- 1 and OC-3 are probably directed against peptide epitopes on the glycoproteins. Since the capsule consists of approximately $60 \%$ total carbohydrate (Oriol et al., 1993), including neutral sugars, amino sugars and sialic acid, it was reasonable to expect that mAbs against the capsule might recognize carbohydrate epitopes.
The possible origin of the capsule has been debated ever since Martin suggested that the trophoblast or endometrium or both are involved in its formation (Martin, 1890). The inability of equine embryos to produce a visible capsule under in vitro conditions has led to the belief that the endometrium participates in its secretion (Betteridge, 1989), whereas other workers have suggested that the zona pellucida is required for capsule formation (Skidmore et al., 1989). However, several observations suggest that the zona pellucida does not contribute to capsule formation. Blastomeres from equine embryos can develop to term after growth within porcine zonae pellucidae incubated in the oviduct of a ewe, before transfer to recipient mares (Allen and Pashen, 1984). In addition, recent studies have shown that zona-free bisected blastocysts can develop a complete capsule after transfer into mares (McKinnon et al., 1989). However, it was not established how soon after transfer the new capsules were deposited around half-embryos, or whether their properties differed from those established in our laboratory (the present study and Oriol et al., 1993). Finally, the period of maximum growth of the capsule, and OC-1-reactive antigen production, occurs long after the disappearance of the zona pellucida, confirming that the capsule does not require the zona for its secretion. However, these observations do not rule out the possibility that the maternal endometrium contributes to the formation of the capsule.

An explanation for the lack of formation of the capsule in vitro may be that its constituent glycoproteins belong to the mucin family, and are, therefore, likely to be secreted in the same manner as other mucins. Mucin glycoproteins are secreted as large glycopeptides, which become fully glycosylated during their passage through the Golgi apparatus (Dekker et al., 1991). However, the gel-like mucus layer is formed later, on the surface of the mucosa, by hydration and crosslinking of the individual mucins (Verdugo, 1991). Reports on secretion of high molecular weight mucins in culture are limited (McCool et al., 1990; Virmani et al., 1992), but assembly of the mucus layer has not been achieved. Under conditions in vitro, any secreted mucins would be expected to disperse in the culture solution rather than to assemble to form a discrete extracellular structure (Verdugo, 1991), because duplication of the required conditions for hydration and crosslinking is difficult. It is, therefore, not surprising that formation of blastocyst coverings in vitro has not been achieved in either the horse (McKinnon et al., 1989; Hinrichs et al., 1990) or the rabbit (Fischer et al., 1991). In addition, it has been suggested that the rabbit neozona is a mucin-type glycoprotein (Denker, 1977), and is secreted in part by the trophoblast (Denker, 1983). Furthermore, it has been shown that several proteins seem to be produced by the rabbit trophoblast in vitro for incorporation into the blastocyst coverings (Henkel et al., 1990). In horses, a group of proteins with molecular mass $>300 \mathrm{kDa}$ is synthesized by the day $12-18$ conceptus in vitro (McDowell et al., 1990). These proteins could be components of the embryonic capsule. We propose, therefore, that the gel-like structure of the capsule is formed, on the surface of the trophectoderm, by hydration and crosslinking of the individual capsular glycopolypeptides, although the nature of these crosslinking bridges remains to be established. It has been proposed that mucus rheology also depends on the 'bottle-brush' characteristics of the mucin, and the electrolyte composition of the environment into which its secreted (Allen, 
1983; Verdugo, 1991). In support of this hypothesis, Flood et al. (1982) observed that delicate fibrils from the cell surface and in particular from the microvilli, were continuous with the fibrils of the developing capsule. In this context, ultrastructural studies on intestinal cells showed the secretion of thin streams of material by intestinal cells, and those streams became part of the mucus (Specian and Neutra, 1980). Thus, studies of secreted embryonic glycoproteins using $m A b$ OC- 1 should be useful in confirming the hypothesis that capsular glycoproteins are secreted by the trophoblast in vitro, but without the formation of a defined capsule.

This study has begun to answer fundamental questions about the synthesis, and developmental changes, of the capsular glycoproteins, and a firm foundation has been laid for determining the biological importance of the capsule, and blastocyst coverings in other species. The mucin-like characteristics of its glycoproteins suggest a potential role for the capsule in protecting the conceptus during the mobile phase (Oriol et al., 1993). The present study indicates an additional role for this structure in embryo fixation. The observed changes in OC-1-reactive antigen expression strongly suggest that capsular glycoprotein secretion can be ascribed, at least in major part, to the trophoblastic cells. In view of the modulated pattern of secretion, and the coincidence of molecular changes in the capsule with important events in early pregnancy, it seems likely that the equine capsule, and analogous blastocyst coverings in other mammals, play a crucial role in early embryonic development, and therefore merit further investigation.

The authors would like to thank A. J. Clarke (Department of Microbiology, University of Guelph) for providing access to amino acid and carbohydrate analysis facilities, D. F. Antczak (Cornell University, Ithaca, NY) for supplying the SP/20 cell line, W. R. Allen (Equine Fertility Unit, Newmarket) for providing two samples of endometrial cup tissue, and B. A. Ball (Comell University, Ithaca, NY), K. Hinrichs (Tufts University, Boston, MA) and D. C. Sharp (University of Florida, Gainesville, FL) for providing some equine capsules for these studies. The authors would like to acknowledge the clinical contributions of W. R. Allen, P. J. Meyers and O. Peck, the statistical advice of B. Allen, and the technical assistance provided by A. Chiu and G. DiDiodato. The financial support of NSERC of Canada, the Equine Research Centre at the University of Guelph and the E. P. Taylor Research Foundation is gratefully acknowledged.

\section{References}

Abe H, Ookata K, Abe M and Oikawa T (1992) Immunological characterization of oviductal glycoproteins associated with the zona pellucida of the golden hamster egg Journal of Experimental Zoology 262 209-218

Allen A (1983) Mucus - a protective secretion complexity Trends in Biochemical Sciences 8 169-173

Allen WR and Pashen RL (1984) Production of monozygotic (identical) horse twins by embryo manipulation Joumal of Reproduction and Fertility 71 $607-613$

Allen WR, Hamilton DW and Moor RM (1973) The origin of equine endometrial cups. II. Invasion of the endometrium by trophoblast Anatomical Record 177 475-501

Antczak DF, Poleman JC, Stenzler LM, Volsen SG and Allen WR (1987) Monoclonal antibodies to equine trophoblast Trophoblast Research 2 199-214

Bara J, Decaens C, Loridon-Rosa B and Oriol R (1992) Immunohistological characterization of mucin epitopes by pre-treatment of gastro-intestinal sections with periodic acid Journal of Immunological Methods 149 105-113
Betteridge KJ (1989) The structure and function of the equine capsule in relation to embryo manipulation and transfer Equine Veterinary Journal Supplement 8 $92-100$

Betteridge KJ, Eaglesome MD, Mitchell D, Flood PF and Bériault R (1982) Development of horse embryos up to twenty-two days after ovulation: observations on fresh specimens jourmal of Anatomy 135 191-209

Bousquet D, Guillomot M and Betteridge KJ (1987) Equine zona pellucida and capsule: some physicochemical and antigenic properties Gamete Research 16 $121-132$

Chávez DJ (1986) Cell surface of mouse blastocysts at the trophectodermuterine interface during the adhesive stage of implantation American Journal of Anatomy 176 153-158

Dekker J, Van Der Ende A, Aelmans PH and Strous GJ (1991) Rat gastric mucin is synthesized and secreted exclusively as filamentous oligomers Biochemical Journal 279 251-256

Denker H-W (1977) Implantation: the role of proteinases, and blockage of implantation by proteinase inhibitors. In Advances in Anatomical Embryology and Cell Biology 53 pp 78-79. Springer, Berlin

Denker H-W (1983) Basic aspects of ovoimplantation. In Obstetrics and Gynecology Annual Vol 12 pp 15-42 Ed. RM Wynn. Appleton-CenturyCrofts, Norwalk, Connecticut

Donaldson WL, Zhang CH, Oriol JG and Antczak DF (1990) Invasive equine trophoblast expresses conventional class I major histocompatibility antigens Development 110 63-71

Draper NR and Smith H (1981) Applied Regression Analysis (2nd ed) pp 252-257. J Wiley and Sons, New York

Enders AC and Liu IKM (1991) Lodgement of the equine blastocyst in the uterus from fixation through endometrial cup formation Joumal of Reproduction and Fertility Supplement 44 427-438

Fischer B, Mootz U, Denker H-W, Lambertz M and Beier HM (1991) The dynamic structure of rabbit blastocyst coverings. III. Transformation of coverings under non-physiological developmental conditions Anatomy and Embryology 183 17-27

Flood PF, Betteridge KJ and Diocee MS (1982) Transmission electron microscopy of horse embryos 3-16 days after ovulation journal of Reproduction and Fertility Supplement 32 319-327

Freeman DA, Weber JA, Geary RT and Woods GL (1991) Time of embryo transport through the mare oviduct Theriogenology 36 823-830

Frixen UH, Behrens J, Sachs M, Eberle G, Voss B, Warda A, Löchner D and Birchmeier W (1991) E-Cadherin-mediated cell-cell adhesion prevents invasiveness of human carcinoma cells Joumal of Cell Biology 113 173-185

Ginther OJ (1985) Dynamic physical interactions between the equine embryo and uterus Equine Veterinary Journal Supplement 3 41-47

Glass RH, Spindle AI and Pedersen RA (1979) Mouse embryo attachment to substratum and interaction of trophoblast with cultured cells joumal of Experimental Zoology 208 327-336

Goding JW (1986) Monoclonal Antibodies: Principles and Practice: Production and Application of Monoclonal Antibodies in Cell Biology, Biochemistry and Immunology. (2nd Edn). Academic Press, London

Guillomot M and Betteridge K (1984) Permeability of the capsule of the equine embryo. Proceedings of the Society for the Study of Fertility. Winter Meeting Abstract 58

Guillomot M, Fléchon J-E and Wintenberger-Torres S (1982) Cytochemical studies of uterine and trophoblastic surface coats during blastocyst attachment in the ewe Journal of Reproduction and Fertility 65 1-8

Henkel R, Dannhorn DR, Petzoldt U and Kirchner C (1990) Ultrastructure, protein synthesis and secretion of day- 6 rabbit blastocyst cultured in a chemically defined, protein-free medium Anatomy and Embryology 182 465-472

Hilkens J, Ligtenberg MJL, Vos HL and Litvinov SV (1992) Cell membraneassociated mucins and their adhesion-modulating property Trends in Biochemical Sciences 17 359-363

Hinrichs K, Schmidt AL, Memon MA, Selgrath JP and Ebert KM (1990) Culture of 5-day horse embryos in microdroplets for 10 to 20 days Theriogenology 34 $643-653$

Jentoft N (1990) Why are proteins O-glycosylated? Trends in Biochemical Sciences 15 291-294

La Bonnardière C, Martinat-Botte F, Terqui M, Lefèvre F, Zouari K, Martal J and Bazer FW (1991) Production of two species of interferon by Large White and Meishan pig conceptuses during the peri-attachment period journal of Reproduction and Fertility 91 468-478

Laemmli UK (1970) Cleavage of structural proteins during the assembly of the head of bacteriophage T4 Nature $227680-685$ 
Lamblin G, Lhermitte M, Klein A, Houdret N, Scharfman A, Ramphal R and Roussel P (1991) The carbohydrate diversity of human respiratory mucins: a protection of the underlying mucosa? American Review of Respiratory Diseases 144 S19-S24

Leiser R and Denker H-W (1988) The dynamic structure of rabbit blastocyst coverings. II. Ultrastructural evidence for the role of the trophoblast in neozona formation Anatomy and Embryology 179 129-134

Ligtenberg MJL, Buijs F, Vos HL and Hilkens J (1992) Suppression of cellular aggregation by high levels of episialin Cancer Research 52 2318-2324

McCool DJ, Marcon MA, Forstner JF and Forstner GG (1990) The T84 human colonic adenocarcinoma cell line produces mucin in culture and releases it in response to various secretagogues Biochemical Journal 267 491-500

McDowell KJ, Sharp DC, Fazleabas AT and Roberts RM (1990) Twodimensional polyacrylamide gel electrophoresis of proteins synthesized and released by conceptus and endometria from pony mares Journal of Reproduction and Fertility 89 107-115

McKinnon AO, Carnevale EM, Squires EL, Carney NJ and Seidel GE (1989) Bisection of equine embryos Equine Veterinary Joumal Supplement 8 129-133

Martin P (1890) Ein Pferdeei vom 21 Tage Schweizer Archiv fur Thierheilkunde 32 101-119

Mason DY, Nalem M, Abdulaziz Z, Nash JRG, Gatter KC and Stein H (1982) Immunohistological applications of monoclonal antibodies. In Monoclonal Antibodies in Clinical Medicine pp 585-635 Ed. AJ McMichael and JW Fabre. Academic Press, New York

Massamiri Y, Durand G, Richard A, Féger J and Agneray J (1979) Determination of erythrocyte surface sialic acid residues by a new colorimetric method Analytical Biochemistry 97 346-351

Miller CC, Fayrer-Hosken RA, Timmons TM, Lee VH, Caudle AB and Dunbar BS (1992) Characterization of equine zona pellucida glycoproteins by polyacrylamide gel electrophoresis and immunological techniques Journal of Reproduction and Fertility 96 815-825

Miller CC, Merkle RK, Brooks PM, Caudle AB and Fayrer-Hosken RA (1993) Carbohydrate and protein analysis of the equine zona pellucida Theriogenology 39268 (Abstract)

Murphy CR and Turner VF (1991) Glycocalyx carbohydrates of uterine epithelial cells increase during early pregnancy in the rat Joumal of Anatomy 177 109-115

Oguri N and Tsutsumi Y (1972) Non-surgical recovery of equine eggs, and an attempt at non-surgical egg transfer in horses Joumal of Reproduction and Fertility 31 187-195

Oriol JG, Poleman CJ, Antczak DF and Allen WR (1989) A monoclonal antibody specific for equine trophoblast Equine Veterinary Journal Supplement 8 14-18

Oriol JG, Beresford B, Sharom FJ and Betteridge KJ (1991a) Biochemical composition of the equine capsule: a preliminary report Journal of Reproduction and Fertility Supplement 44 639-641

Oriol JG, Donaldson WL, Dougherty DA and Antczak DF (1991b) Molecules of early equine trophoblast Joumal of Reproduction and Fertility Supplement $\mathbf{4 4}$ 455-462

Oriol JG, Betteridge KJ, Clarke AJ and Sharom FJ (1993) Mucin-like glycoproteins in the equine embryonic capsule Molecular Reproduction and Development 34 255-265
Parrish CR, Carmichael LE and Antczak DF (1982) Antigenic relationships between canine parvovirus type 2, feline panleukopenia virus, and mink enteritis virus using conventional antisera and monoclonal antibodies Archives of Virology 72 267-278

Pintus C, Ransom JH and Evans CH (1983) Endothelial cell growth supplement: a cell cloning factor that promotes the growth of monoclonal antibody producing hybridoma cells Joumal of Immunological Methods 61 195-200

Roberts RM (1989) A novel group of interferons associated with the early ovine and bovine embryo Joumal of Interferon Research 9 373-378

Roux E and Kan FWK (1991) Changes of glycoconjugate contents of the zona pellucida during oocyte growth and development in the golden hamster; a quantitative cytochemical study Anatomical Record 230 347-360

St-Jacques S, Malette B, Chevalier S, Roberts KD and Bleau G (1992) The zona pellucida binds the mature form of an oviductal glycoprotein (oviductin) Joumal of Experimental Zoology 262 97-104

Sharp DC, McDowell KJ, Weithenauer J and Thatcher WW (1989) The continuum of events leading to matemal recognition of pregnancy in mares Joumal of Reproduction and Fertility Supplement 37 101-107

Sirois J and Betteridge KJ (1988) Transcervical collection of equine conceptuses between 10 and 16 days after ovulation Theriogenology 30 1139-1148

Skidmore J, Boyle MS, Cran D and Allen WR (1989) Micromanipulation of equine embryos to produce monozygotic twins Equine Veterinary Journal Supplement 8 126-128

Specian RD and Neutra MR (1980) Mechanism of rapid mucus secretion in goblet cells stimulated by acetylcholine Journal of Cell Biology 85 626-640

Verdugo P (1991) Mucin exocytosis American Review of Respiratory Diseases 144 S33-S37

Virmani AK, Naziruddin B, Desai VC, Lowry IP, Graves DC and Sachdev GP (1992) Evidence for secretion of high molecular weight mucins by canine tracheal epithelial cells in primary culture: effects of select secretagogues on mucin secretion. In Vitro Cell Developmental Biology 28A 120-127

Wassarman PM (1988) Zona pellucida glycoproteins Annual Review of Biochemistry 57 415-442

Whyte A and Allen WR (1985) Equine endometrium at pre-implantation stages of pregnancy has specific glycosylated regions Placenta 6 537-542

Wimsatt WA (1963) Delayed implantation in the Ursidae, with particular reference to the black bear (Ursus americanus Pallas). In Delayed Implantation pp 49-76 Ed. AC Enders. William Marsh Rice University by University of Chicago Press, Chicago

Wordinger RJ and Amsler KR (1980) Histochemical identification of the glycocalyx layer in the bovine oviduct and endometrium Animal Reproduction Science 3 189-193

Wray W, Boulikas T, Wray VP and Hancock R (1981) Silver staining of proteins in polyacrylamide gels Analytical Biochemistry 118 197-203

Yang P, Yin X and Rutishauser U (1992) Intercellular space is affected by the polysialic acid content of NCAM Joumal of Cell Biology 116 1487-1496

Zouari K, Bèzard J, Reinaud P, Guillomot M, Palmer E and Martal J (1991) Evidence for the presence of equine trophoblastic interferons during early pregnancy Journal of Interferon Research Supplement 1 S134 